\title{
Determination of Optimum Preservative Treatment Time for Green Bamboo using Boucherie Apparatus: Jagriti
}

\author{
Dhruba Gurung ${ }^{1}$, Runumi Borthakur ${ }^{2}$, R. K. Borah ${ }^{3}$
}

\begin{abstract}
The Boucherie Process is one of the processes for preservative treatment of bamboo to enhance its durability. Various authors have reported a treatment time of 3 - 7 hours for 12' long bamboo and 30-60 min to treat short length bamboos using pressures of up to $2 \mathrm{~kg} / \mathrm{cm}^{2}$ without mentioning the completion of treatment process. Further literature survey did not reveal any procedure for preservative treatment of bamboos and completion of the treatment process. In the present study the preservative treatment protocol was developed and tested using Boucherie apparatus (Jagriti) on Bambusa pallida using the pressure between 1 to $1.5 \mathrm{~kg} / \mathrm{cm}^{2}$. The completion of treatment process was estimated by comparing the Specific gravity of the treating solution and the effluents at an interval of five minutes using the specific gravity bottles. It was found that freshly harvested bamboo of a meter length required only 15-20 minutes for completion of the process at 1 to $1.5 \mathrm{~kg} / \mathrm{cm}^{2}$. Longer treatment time was observed due to the presence of particulate matters in the treating solution or on cut surface of bamboo. Post harvest delay also contributed to longer treatment time. There was a significant difference in the treatment time required among the different portions of bamboo and also when the treatment was given 1-2 days after harvest.
\end{abstract}

Keywords: Durability, Modified Boucherie process, Preservative treatment time.

\section{Introduction}

Bamboo finds multifarious uses but its natural durability is very low due to damage caused by insects and fungi (Beeson, 1941; Kumar et al., 1994). Various methods are employed to enhance its durability by age old traditional methods and by using modern scientific methods which employ chemical preservatives. These preservative chemical are instilled into the bamboos by various process like steeping, soaking, Boucherie process etc. To enhance the durability of bamboo different techniques are employed viz. traditional and chemical. The traditional methods employ curing, water submergence, smoking, drying and lime/tar coating. In chemical preservation of bamboo various methods and chemicals are used to enhance its durability like Boucherie process, Vacuum process, Fell-cell process, Empty cell process etc. In terms of penetration, distribution and retention of preservatives Boucherie method is considered one of the best methods (Liese, 1980; Gnanaharan, 2000). Initially the Boucherie process was used to treat green timber with the help of motor tyre tubes or a container connected to such tube, containing the chemical preservative is referred to as the "Boucherie Process (Purushotham et al, 1953, Shukla and Dev, 2000). This system of preservative treatment is basically a sap replacement process, which is still practised by placing a tank high enough to create sufficient hydrostatic pressure for preservative treatment (Liese \& Kumar, 2003).

The "Modified Boucherie Process" differs from the earlier version is the use of cycle pump to increase pneumatic pressure on the preservative (Purushotham et al., 1953). The Modified Boucherie process can be utilized for preservative treatment of freshly harvested green bamboo with or without branches and leaves. The use of simple hand or foot pump to generate suitable pressure reduces the period of treatment time significantly. The penetration and absorption of the preservative depends upon several factors such as concentration of solution, treatment time, nature of chemicals used, dimensions of the bamboo, its age and moisture content. It was reported to takes $30-60 \mathrm{~min}$ to treat short bamboo lengths using pressures up to $2 \mathrm{~kg} / \mathrm{cm}^{2}$ (Singh, 1968; Kumar et al., 1994). In order to obtain uniform distribution of preservative from bottom to top, it is recommended to initially use a concentrated solution (6\%) until the solution drips out of the apical end. This should be followed by pumping in a solution of a lower concentration (2\%) for the same period of time. But further literature survey did not reveal the exact procedure for preservative treatment of bamboo; the time it is supposed to be completed and the time taken for completion of the preservative treatment. Treatment time for $6 \mathrm{~m}$ long bamboo is 3 hrs for interior use and 6 hrs for exterior use (Anon, 2006).

\section{Material and Method}

Commonly available bamboo namely Bambusa pallida Munro (Bijuli bah) of 3-4 years of age was harvested on a daily on requirement basis, cut and sized to $1 \mathrm{~m}$ length and separated into top (R1), mid (R2) and bottom (R3) portions. The chemical preservative used was Copper Chrome Boron (CCB), procured from ASCU Arch Timber Protection Limited, 3524 D-Hide Road Extension Kolkata 700088. India. The weight of $10 \mathrm{ml}$ of the filtered water to be used for preparation of preservative solution was recorded using the $10 \mathrm{ml}$ capacity specific gravity bottle and electronic balance (Model: Sartorius). Similarly the weight of the treating preservative solution of CCB in the concentrations of $8 \%, 10 \%$ and $12 \%$ were also recorded up to four decimal points as and when it was prepared. The bamboo samples of $1 \mathrm{~m}$ length were treated by locally designed and fabricated Boucherie apparatus - Jagriti (Fig:1) (Patent No: 231745 Dated 09.03.2009) with the selected preservative under pneumatic pressures of 1 to $1.5 \mathrm{~kg} / \mathrm{cm}^{2}$ generated by foot pump. 


\section{International Journal of Science and Research (IJSR) ISSN (Online): 2319-7064}

Index Copernicus Value (2013): 6.14 | Impact Factor (2014): 5.611

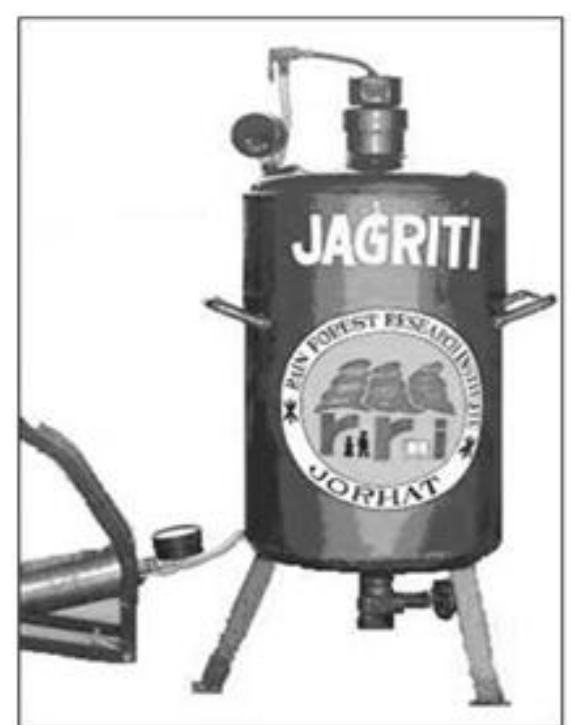

Figure 1: Jagriti: the Boucherie apparatus

With the initiation of treatment process, effluents' emerging from the distal end of bamboo was collected at an interval of every 5 minutes and the weight of $10 \mathrm{ml}$ of the effluent collected was recorded. The specific gravity of the effluent was compared with that of the treating solution to determine the completion of the treatment process (Table 1). The bamboo samples which could not be given preservative treatment on the day of harvest were kept submerged in water which was given the preservative treatment within the next two days. A thin slice of bamboo was cut to reveal the fresh tissues, washed with clean water before they were attached to the Boucherie apparatus for preservative treatment process. The preservative treatment process was deemed complete when the specific gravity of the effluent became equal that of the treating solution to four decimal points. The preservative treatment process was continued for sometime even after the completion of the treatment to see if any changes takes place in specific gravity of the effluents with time. Since only fresh bamboo samples were used in the study their moisture content was not recorded. The data on preservative treatment time required to complete the process were analyzed with ANOVA at CD (Critical Difference) 5\% (Gomez \& Gomez. 1984).

Table 1: Protocol for determination of completion of treatment process

\begin{tabular}{|c|c|c|c|}
\hline $\begin{array}{c}\text { Wt of effluent } \\
(10 \mathrm{ml})\end{array}$ & $\begin{array}{c}\text { Time } \\
(\mathrm{min})\end{array}$ & $\begin{array}{c}\text { Specific gravity } \\
\text { of effluent }\end{array}$ & $\begin{array}{c}\text { Specific gravity of } \\
\text { treating solution }\end{array}$ \\
\hline 29.829 & 5 & 1.0094 & 1.0205 \\
\hline 30.046 & 10 & 1.0168 & 1.0205 \\
\hline 30.070 & 15 & 1.0176 & 1.0205 \\
\hline 30.073 & 20 & 1.0177 & 1.0205 \\
\hline 30.110 & 25 & 1.0190 & 1.0205 \\
\hline 30.133 & 30 & 1.0197 & 1.0205 \\
\hline 30.142 & 35 & 1.0200 & 1.0205 \\
\hline 30.145 & 40 & 1.0201 & 1.0205 \\
\hline 30.150 & 45 & 1.0203 & 1.0205 \\
\hline 30.153 & 50 & 1.0204 & 1.0205 \\
\hline 30.156 & 55 & 1.0205 & 1.0205 \\
\hline Weight of water (10 ml)=29.55 \\
\hline \multicolumn{4}{|r|}{ Weight of treating solution $(10 \mathrm{ml})=30.156$} \\
\hline
\end{tabular}

\section{Results and Discussion}

The preservative treatment time required for different portions of Bambusa pallida, irrespective of post harvest treatment given, is presented in Table 3. The average preservative treatment time required (Table:2) in Bambusa pallida were 51.50, 46.67 and 54.33 minutes for apical, mid and basal portions respectively, which indicate that lesser average preservative treatment time for the mid portion of the bamboo and higher for the apical and basal portions. Statistical analysis (ANOVA) of the data (Table 3) of the data show that there is a significant difference among the preservative treatments at $5 \%$ level of probability.

To see the effect of post harvest delay on the completion of preservative treatment, the data (Table 2) were segregated into three categories viz. preservative treatment given to bamboo on the day of harvest, delay of one day and two days and presented as graph 1 . It was found that in case of those bamboo samples which were given preservative treatment on the day of harvest, the average treatment time needed for completion of preservative treatment was 49.44, 35.36 and 44.36 minutes for apical, mid and basal portions of $B$. pallida respectively. When the preservative treatment was given after a delay of one day after harvest the treatment process was completed in 55.00, 39.00 and 52.86 minutes for apical, mid and basal portions respectively and after a delay of two days of harvest the preservative treatments were completed in 56.67, 85.83 and 86 minutes for apical, mid and basal portions respectively (Graph: 1).

Table 2: Preservative treatment time (minutes) required for completion of the process using Jagriti: the Boucherie apparatus in B. pallida

\begin{tabular}{|c|c|c|c|}
\hline S. No & Apical & Mid & Basal \\
\hline 1 & 50 & 50 & 60 \\
\hline 2 & 40 & 75 & 65 \\
\hline 3 & 35 & 45 & 60 \\
\hline 4 & 45 & 45 & 45 \\
\hline 5 & 45 & 35 & 35 \\
\hline 6 & 35 & 50 & 30 \\
\hline 7 & 35 & 30 & 55 \\
\hline 8 & 50 & 25 & 60 \\
\hline 9 & 20 & 45 & 75 \\
\hline 10 & 50 & 25 & 85 \\
\hline 11 & 65 & 145 & 105 \\
\hline 12 & 95 & 35 & 95 \\
\hline 13 & 55 & 40 & 60 \\
\hline 14 & 60 & 50 & 105 \\
\hline 15 & 55 & 60 & 60 \\
\hline 16 & 25 & 20 & 30 \\
\hline 17 & 25 & 15 & 15 \\
\hline 18 & 80 & 25 & 40 \\
\hline 19 & 70 & 30 & 40 \\
\hline 20 & 50 & 25 & 45 \\
\hline 21 & 25 & 40 & 35 \\
\hline 22 & 25 & 50 & 25 \\
\hline 23 & 25 & 20 & 60 \\
\hline 24 & 15 & 20 & 30 \\
\hline 25 & 40 & 35 & 65 \\
\hline 23 & 90 & 90 & 40 \\
\hline 27 & 85 & 70 & 25 \\
\hline 28 & 70 & 95 & 65 \\
\hline 29 & 70 & 70 & 15 \\
\hline 30 & 115 & 40 & 105 \\
\hline Mean & 51.50 & 46.67 & 54.33 \\
\hline
\end{tabular}




\section{International Journal of Science and Research (IJSR) \\ ISSN (Online): 2319-7064 \\ Index Copernicus Value (2013): 6.14 | Impact Factor (2014): 5.611}

The study indicate that when the bamboo samples of $1 \mathrm{~m}$ length were treated on the day it is harvested, apical portion needed the longest time averaging 49.44 minutes for completion of the preservative treatment process. It was followed by basal portion where the preservative treatment process was completed in an average of 44.38 minutes. The middle portion of the bamboo required the least time of 35.36 minutes (average) to complete the treatment process. When the preservative treatment was carried out after one day after harvest, the average time needed to complete the process were $55.00,39.00$ and 52.86 minutes respectively for apical, mid and basal portions respectively. But when the preservative treatment was given after two days of harvest, the time needed to complete the process was 56.67, 85.83 and 86.00 minutes respectively which are different from the trends seen in the case of treatments given on the day of harvest and after one day of harvest.

In case of preservative treatment of apical portion of $B$. pallida, there is an increase in completion of treatment process from 48.44 (mean) minutes treated on the day of harvest to 55.00 (mean) minutes after storage of one day which further increased to 56.67 (mean) minutes after storage of two days. The preservative treatment time required in mid portion of $B$. pallida was 35.36 (mean) minutes when it was given preservative treatment on the day of harvest which increased to 39.00 (mean) minutes and 85.83 (mean) minutes ( $\sim 1 \mathrm{hr} 26$ minutes) after storage of one and two days respectively. In case of basal portion of B. pallida the preservative treatment time needed was 44.38 minutes (mean) when it was given preservative treatment on the day of harvest, it increased to 52.86 (mean) minutes and 86.00 (mean) minutes ( 1 hr. 26 minutes) after the storage period of one and two days respectively. This increase in longer treatment time required for completion of the treatment process may be attributed to gradual post harvest anatomical changes in bamboo, which occur by way of the precipitation of the sap in the vessels and clogging of the flow pathways to the adjacent tissues (Kumar et al. 1994).

The precautions to be adhered to during the preservative treatment of bamboos using Boucherie apparatus is that the preservative solution should not contain any particulate matters in it and also there should not be any debris adhering to the cut surface of bamboo attached to the apparatus. The bamboos should be harvested on day to day requirement basis, as storage of bamboo for longer duration cause anatomical changes in bamboo resulting in longer duration to complete the treatment process.

Table 3: Analysis (ANOVA) of preservative time required for treatment of B. pallida

\begin{tabular}{|c|c|c|c|c|c|c|}
\hline Source of variation & Degree of freedom & Sum of squares & Mean squares & F calculated & Tabular F 5\% & Significance \\
\hline Replications & 29 & 32329.2 & 1115 & 2.41 & 1.65 & Sig \\
\hline Portion of bamboo & 2 & 902 & 451 & 0.97 & 3.15 & NS \\
\hline Error & 58 & 26832 & 463 & \multicolumn{3}{c}{} \\
\cline { 1 - 5 }
\end{tabular}

SED : 27.26 CD 45.55

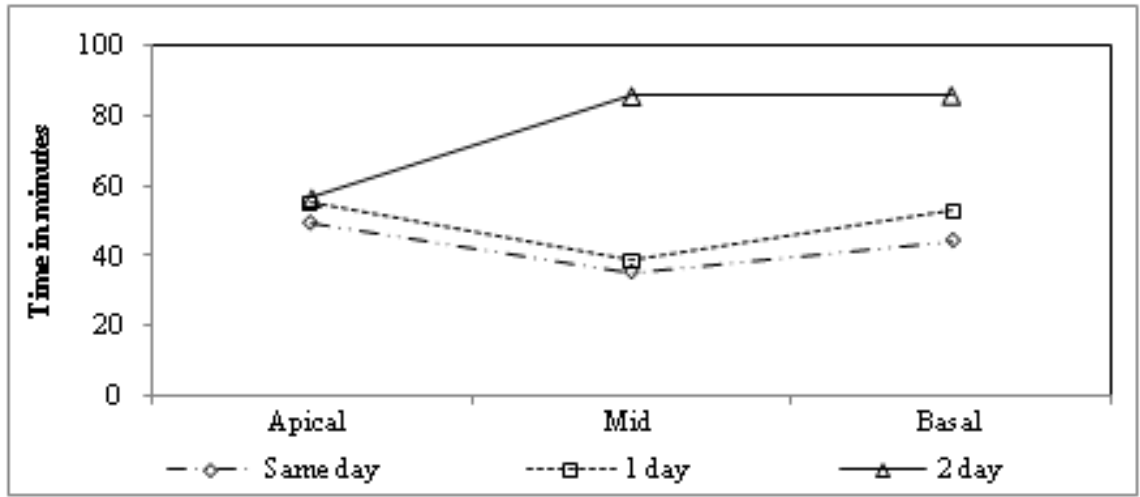

Graph 1: Effect of post harvest delay on completion of preservative treatment using Boucherie Apparatus - Jagriti

\section{References}

[1] Anonymous (2006). Preservation of bamboo- Training Manual TM 05 07/06. National Mission on Bamboo Application (NMBA). Technology Information Forecasting and Assessment Council (TIFAC). Dept. of Science and Technology. Govt. of India.

[2] Beeson, C.F.C. (1941). Ecology and Control of Forest Insects of India and Neighboring Countries, Vasant Press, Dehra Dun.

[3] Gnanaharan, R. (2000). Preservative Treatment Methods for Bamboo: A Review. PART-II Kerala Forest Research Institute, Peechi, Thrissur. KFRI Research Report 177(ii)
[4] Gomez, K. A. \& Arturo A. Gomez. (1984). Statistical procedures for Agricultural Research. John Wiley \& Sons. Singapore. 1984.

[5] Kumar, S. Shukla, K.S. Dev, I. and Dobriyal, P.B. (1994). Bamboo Preservation Techniques: A Review. INBAR Technical Report No.3. INBAR, New Delhi and ICFRE, Dehradun. 59 pp.

[6] Liese, W. (1980). Preservation of bamboos. In: (G. Lessard and A. Chouinard, eds). Bamboo Research in Asia. IDRC, Canada. pp. 165-172.

[7] Liese, W., S. Kumar. (2003). Bamboo Preservation Compendium. Centre for Indian Bamboo Resource and Technology (CIBART) Technical Report 1. 200 Jor Bagh, New Delhi. India.p-231. 


\section{International Journal of Science and Research (IJSR) \\ ISSN (Online): 2319-7064}

Index Copernicus Value (2013): 6.14 | Impact Factor (2014): 5.611

[8] Purushotham, A., Sudan, S.K. and Sagar, V. (1953). Preservative treatment of green bamboos under low pneumatic pressures. Indian Forester 79: 652-672.

[9] Shukla, K. S.; Indra Dev (2000). Boucherie process: a review. Jour. Timber Development Association of India. Vol. 46 No. 3/4 pp. 33-40

[10] Singh, S. and Nigam, P.N. (1968). Note on preservation of green bamboos by the modified Boucherie and the diffusion process. Journal of Timber Development of India, 14(1): 20-23. 